\title{
The Astrobiological Landscape: Philosophical Foundations of the Study of Cosmic Life. By Milan M. Ćirković
}

\author{
The Astrobiological Landscape: Philosophical Foundations of the \\ Study of Cosmic Life. By Milan M. Ćirković, Cambridge University \\ Press, Cambridge, 2012, 266 pp. \$107.82 (USD) (hardcover) ISBN \\ 9780521197755
}

\section{Charles H. Lineweaver}

Received: 5 October 2014 / Accepted: 6 October 2014 /

Published online: 1 November 2014

(C) Springer Science+Business Media Dordrecht 2014

Astrobiologists wrestle daily with the unwieldy question: Are we alone? If you are interested, read this authoritative book and give yourself an inspirational voyage to the habitable islands of the multiverse. Ćirković's book is not an astrobiology textbook with facts and worked examples, but it is probably the best book on the philosophical implications of life in the universe, in the universe. This book describes itself as "the first systematic survey of the philosophical aspects and conundrums in the study of cosmic life." and is "a philosophical exploration of perplexing issues arising from contemporary research on the origin, existence and future of life in its widest cosmological context." (p4). These descriptions are accurate. The book is well-written, with long sentences that make sense, with commas, in the right, places.

Like a good scientific result, this book raises and resusitates more questions than it answers - and in making these new questions more explicit, it offers us the most constructive gift that the philosophy of cosmology and biology can give to astrobiology. Instead of the chemical details of "Why Nature Chose Phosphates" (Westheimer 1987), Ćirković challenges himself and the astrobiological community to investigate what it is about our universe that makes observers possible.

Milan Ćirković is a well-read polymath, science fiction enthusiast, Leonard Cohen fan and Serbian astronomer/historian/philosopher at the Astronomical Observatory of Belgrade. He has been prolific on selection effects in cosmology, multiverses, the history of human conceptions of extraterrestrials, SETI, and existential threats to humanity (e.g. Bostrom and Ćirković 2008). Like all of Ćirković's work, this book is an insightful, authoritative window into the professional literature, where "professional literature" includes history, cosmology, philosophy, physics, evolutionary biology, SETI and the best science fiction. Unlike most astrobiologists, he is as informed about the history of the subject as he is about its current state. In this way he reminds me of Steven J. Gould and Antonio Lazcano. He gives us a tour de

C. H. Lineweaver $(\bowtie)$

Research School of Astronomy and Astrophysics and Research School of Earth Sciences, Australian National University, Canberra, ACT, Australia

e-mail: charley.lineweaver@anu.edu.au 
force of multi-disciplinary analysis as he bequeaths to the field a comprehensive bibliography. His 215 pages of text are backed up with 21 pages of notes and 22 pages of references. As another example of his bibliographic prowess see Ćirković (2003) on what is known about how the universe will end. Almost all good science papers have an introductory paragraph in which the history of the problem is concisely reviewed. If your papers are in the field of astrobiology, your introductory paragraph will be made more complete and accurate by consulting this book and its 22 page bibliography.

Ćirković is probably at his best in his discussion of corrections for observer selection effects (Chapter 3). So, if you're confused about the anthropic principle, reading this book will help you avoid the many unmarked pitfalls of anthropic reasoning.

We can study the origin of life in two ways. The most straight-forward way is to worry about how life on Earth got started without worrying about aliens. Scientists in this group ask "How DID life get started?" I will refer to this group as biochemists. The other way is, worry about aliens and ask "How DOES life get started?" This is the astrobiological way. Thus, the difference between speculation-averse biochemists and visionary astrobiologists comes down to the difference between DID and DOES. Ćirković is a DOES man. Astrobiologists try to identify the most fundamental features that could be generic to the origins of life elsewhere in the universe. Biochemists may find it hard to excuse astrobiologists for ignoring the "quirky" features of life. Biochemists can also accuse astrobiologists of hypothesizing (without evidence) the existence of a large imaginary set of alternative molecular evolutionary pathways that have supposedly led to life elsewhere. Astrobiologists pretend that the origin of life on Earth followed one of many pathways that (they suppose) have already led to the origin of life elsewhere in the universe. On their view (and Ćirković's), the origin of life on Earth is a specific example of the set of processes that have led to life elsewhere.

Ćirković identifies two main strands in his book - what he calls Copernicanism and continuity. Everyone agrees with Copernicus. The Sun does not go around the Earth. We are not in the middle...spatially. But are we, the life forms of Earth, in the middle... chemically....evolutionarily? Are we humans a typical product of the evolution of life ? These are two important questions that Ćirković spends the majority of the book discussing - most of it on the less tractable second one. Whether we (the life forms on Earth) are in the middle chemically is a question about biogenesis - the origin life. Whether we (homo sapiens) are in the middle evolutionarily, is a question about noogenesis - the origin of human-like intelligence. Ćirković thinks the answer to both of these is yes. He is in good company (De Duve 1996, Sagan 1995). His arguments are largely based on what he calls the "extended continuity thesis":

"I suggest an extended continuity thesis, which brings the reasoning of Fry (2000) to its logical conclusion, namely that there are no unbridgeable gaps between simple life and a complex one, and between complex life and an intelligent one (possibly also between biological intelligent life and a postbiological intelligent one). Whenever and wherever physical, chemical, ecological, etc. conditions are suitable, the emergence of complex life is highly probable - and ditto for intelligent life." (p143)

But, how common are the conditions that are "suitable"? Since we don't have a good idea of what suitable conditions are, it seems to me they could be common; they could be rare, or they could even be a set of measure zero. Ćirković assumes they are common and that "noogenesis is a continuous part of universal evolution" (p148). He seems to believe that human-like intelligence is so universally adaptive that it is a natural product of the continuity of evolution. Mayr and Sagan had an interesting debate about this (Mayr 1994, 1995, Sagan 1995). Ćirković is on Sagan's side of the debate. I seem to be on the other (Lineweaver 2005, 2009).

The battle ground of the debate is the spectrum between deterministic physics and chemistry on the one hand, and the contingencies of biology and history on the other. 
Evolutionary biology and history seem to be "one damn thing after another". However, even in biology, there is a contingency vs convergence debate: Gould's evolution (Gould 1987) is highly contingent, while Conway-Morris' evolution is highly convergent (Sterelny 2005). Ćirković gives us a nice analysis of this controversy and the most insightful (and I think correct) take on this debate is on page 125: "we cannot ever be sure that it was not similarity of initial conditions that is responsible for a particular observed convergence". If this is the case, then the many examples of "convergence" claimed by evolutionary biologists (e.g. Conway Morris 2003) cannot be extrapolated to alien life, since alien life will have different initial conditions. But if so, why is Ćirković so sure that human-like intelligences are common in the universe? I don't know... but he restates it in many ways:

"there is no unbridgeable gap between inorganic matter systems and living systems and intelligent systems and cultural systems. These are steps in the evolutionary chain of truly "cosmic evolution"." (p168)

How unbridgeable a gap is depends on how specific the result is. It depends on whether we (life forms on Earth) are typical of life in the universe, or whether we (homo sapiens) are typical of intelligent beings in the universe. But since we don't know if there is life elsewhere, we don't know how specific we are. We can make informed guesses (e.g. Lineweaver 2006) but I don't understand why Ćirković thinks that the continuity thesis is compelling evidence for life elsewhere and human-like intelligence elsewhere.

"..I shall regard the existence of terrestrial intelligent observers and our present technological civilization as a fully naturalistic consequence of the evolution of matter in the cosmic context." (p143)

"...as long as we stick to the naturalistic account of all major evolutionary transitions ....Fry's reasoning continues to work inexorably." (p 143)

But, limiting ourselves to naturalistic accounts of life does not mean that life is a cosmic imperative. Natural Darwinian explanations of terrestrial life do not imply that terrestrial type life, or life of any kind is common, or even existent somewhere else in the universe. Naturalistic Darwinian explanations for the evolution of African elephants does not mean that African elephants are inevitable elsewhere in the universe. Natural explanations in evolutionary biology and history (both rich in contingency) do not imply that the result is commonplace (Gould 1987).

Ćirković critique's what he calls the "biological contingency argument" (Simpson 1964):

"The argument is based on the arbitrary, and in fact hitherto undermined, assumption that the particular part of biological morphospace corresponding to intelligent or communication-capable beings is congruent with the part of the morphospace corresponding to humanoids." (p 18, see also Ćirković 2012)

I searched the book for the hitherto undermining evidence and found only restatements of the continuity hypothesis, and a firm belief in Carl Sagan's belief that there may be many different evolutionary pathways to "functionally equivalent humans" (Sagan 1995).

Ćirković sees it as his duty to "cleanse the remnants of wishful thinking, exclusivism and anthropocentrism of any sort from our astrobiological discourse." ( $p$ 182)

"By finishing the unfinished business of the Copernican revolution, astrobiology offers to deprive us of not only self-aggrandaizing and hubristic concoctions and relics of a prescientific age, but also of concepts built into the foundations of human exceptionalism."(p211)

Ćirković thinks that noogenetic Copernicanism - the idea that "everybody is probably just like we are" - is a humble antidote to anthropocentric hubris. But it seems like the opposite to me. There is an important difference between these two ideas:

(1) we are unique - just like every other species.

(2) we are unique - and therefore better than other species. 
Ćirković accuses us of having "exclusivist and anthropocentric illusions", i.e. he accuses us of thinking (2). I found no hint of (1) in the book. This is unfortunate because many of us think (1) is the more appropriate description of our place in the universe.

If the Danish thought that they were a typical outcome of human evolution and went searching for Danish-speaking smorgasborg-eating organisms on rocky planets, that would be taking Copernicanism too far. Just because there is continuity between australopithecines and modern Danes does not mean that Danogenesis is a "continuous part of universal evolution". It smacks more of Denmark-centrism and narcissism than humility. Similarly, to postulate a universe full of functionally-equivalent humans (or even just a few) is the epitomy of anthropocentrism, not Copernican humility. Recognizing that humans are unique, just like every other species, is not exclusivist anthropocentrism, but a recognition of the quirky, nonuniversality of human-like intelligence. Although I disagree with Ćirković's conclusions on this point (Lineweaver 2005, 2009) I have not come across a more detailed airing of this controversy than is found in Ćirković's book.

Biochemists interested in the origin of life will find almost no biochemistry or molecular evolution in the book, but the origin of homochirality does get a mention (p 13). Maybe philosophers just don't do biochemistry. This is unfortunate because the next big step in planetary science is to move beyond finding Earth-sized rocky planets in habitable zones, to the investigation of the planetary chemistries and atmospheres needed for habitability. Here, biochemistry is essential for progress since it's impossible to talk about habitability and the potential for life elsewhere, without talking about the biochemistry of the inhabitants.

Since Ćirković is a European scholar and philosopher, Anglo-American readers may be confused by some of his jargon: "Wallace has understood the empirical basis of anthropic reasoning in the modern disteleological sense." (p 30). And by his valiant attempt to distinguish "eternal" from "everlasting" (p37). And by his legal scholar's penchant for overpeppering the text with italicized Latin. Why he has done this, ignorabimus (we will not know). Maybe you can still get away with this at Oxford. Here are a few Latin phrases from the book that will be of interest to ambitious literati (sensu latu):

sensu latu (broad sense)

ceteris paribus (with all other things being equal)

ars longa, vita brevis (art lasts but life is short)

post festum (after the feast, i.e. too late)

inter alia (among other things)

noogenesis (emergence of intelligent life forms)

ouroboros (tail-devouring snake)

Oikumene (the inhabited world)

mutatis mutandis (only the necessary changes having been made)

The basic assumption of the book, and one that is very common among scientists who have turned their thoughts to the origin of life on Earth, is that a large set of processes exist that can be called "The-origins-of-life-anywhere-in-the -universe", and the process that led to the origin of life on Earth is a subset of this larger set. The problem with this view is that the larger set has been invented based on a controversial reading of terrestrial biochemistry and evolution.

Summary: This book is the best book to read if you want authoritative access to the best literature in the historical precedents of astrobiology, cosmological selection effects and the deep philosophical implications of astrobiology. Regarding its evaluation of intelligent aliens, the discussion is comprehensive and informative. Ćirković examines these questions in more depth and with more authority than any other work I've read - but underlying the authoritative discussion are assumptions that make the reasoning circular. This is an important book with an 
important flaw. Others will hopefully disagree and be able to enjoy the entire book. With him, or agin him, this book motivates us to make an even more careful analysis of whether there are, beyond Earth, aliens with human-like intelligence.

\section{References}

Bostrom N, Ćirković MM (2008) Global Catastrophic Risks. Oxford Univ. Press

Ćirković M (2003) Resource Letter: PEs-1: Physical eschatology”, American Journal of Physics, 71, 122. doi:10. $1119 / 1.1528470$

Ćirković MM (2012) A one hour video of a Ćirković talk at Oxford is a brief introduction to his book and a critique of Simpson's 1964 argument of biological contingency. It can be found at: www.youtube.com/ watch?v $=2 \mathrm{aLex}-21$ myo

Conway Morris S (2003) Life's Solution: Inevitable Humans in a Lonely Universe. Cambridge University Press, Cambridge

De Duve C (1996) Vital Dust: The Origin and Evolution of Life on Earth, Basic Books

Fry I (2000) The Emergence of Life on Earth: A Historical and Scientific Overview. Rutgers Univ. Press, New Brunswick

Gould SJ (1987) The Flamingo's Smile: Reflections in Natural History. NY: W.W. Norton

Lineweaver CH (2005) Astrobiology, 5, 5, Book Review of "Intelligent Life in the Universe: From Common Origins to the Future of Humanity" by Peter Ulmschneider

Lineweaver CH (2006) "We have not detected Extraterrestrial Life: or Have We?" in "Life as We Know It", edt. J. Seckbach Vol 10 of a series on Cellular Origins and Life in Extreme Habitats and Astrobiology, Springer, Dordrecht pp 445-457 ISBN 1-4020-4394-5

Lineweaver CH (2009) Paleontological Tests: Human-like Intelligence is not a Convergent Feature of Evolution" in "From Fossils to Astrobiology", edt. J. Seckbach \& M. Walsh Vol 13 of a series on Cellular Origins and Life in Extreme Habitats and Astrobiology, Springer, pp 353-368

Mayr E (1994) Does it pay to acquire high intelligence? Perspect Biol Med 37(3):337-338

Mayr E (1995) Can SETI Succeed? Not LIkely. Bioastronomy News 7(3), available online at www.astro.edu/ $\sim$ mhanner/Lecture_Notes/Sagan-Mayr.pdf

Sagan C (1995) The abundance of life-bearing planets. Bioastronomy News 7(4) available online at www.astro. umass.edu/ mhanner/Lecture_Notes/Sagan-Mayr.pdf

Simpson GG (1964) The non-prevalence of humanoids. Science 143:769-775

Sterelny K (2005) Another view of life. Stud Hist Phil Biol Biomed Sci 36:585-593

Westheimer FH (1987) Why Nature Chose Phosphates. Science 235:1173 